\title{
Access Clinic: A student-run clinic model to address gaps in the healthcare needs of the homeless population in Adelaide
}

\section{Laalithya Konduru}

\section{Background \\ The average life expectancy of people who are homeless is approximately 20 years lower than the general population. Lack of access to healthcare is one of the key contributors to the increased morbidity and mortality.}

\section{Objective}

The aim of this article is to describe a student-run clinic that was established at a homeless shelter in Adelaide, Australia, to improve healthcare access for individuals who are homeless.

\section{Discussion}

By enhancing the target population's health literacy, the clinic functioned as a bridge between healthcare services and individuals experiencing homelessness who were disengaged from society. Such clinics, if encouraged, can foster a symbiotic relationship where students learn clinical medicine while gaining experience in providing healthcare to vulnerable individuals, and individuals who are homeless can access muchneeded services in an environment they already engage with and feel safe in.
ARTICLE 25.1 of the Universal Declaration of Human Rights makes access to healthcare a basic human right. ${ }^{1}$ Although all Australian residents have access to affordable healthcare through the Medicare Benefits Schedule (MBS), significant challenges still remain to ensure equitable access for all. Some of these challenges stem from the impediments to help-seeking behaviour. In the case of people who are homeless, the impediments are stigma attached to being homeless, and a fear of discrimination leads to to a lack of trust.

The rate of homelessness in Australia was 50 out of every 10,000 people according to the 2016 Australian Bureau of Statistics Census; this was a $5 \%$ increase over the 2011 figures. ${ }^{2}$ With a rate of 37.1 out of every 10,000 people in 2016 , South Australia saw a $7 \%$ increase in the rate of homelessness during the same period. ${ }^{2}$ Although they comprise $<1 \%$ of the total Australian population, individuals who are homeless shoulder a disproportionate burden of morbidity and mortality, with a life expectancy of just 47 years, compared with 77 years for the general population. ${ }^{3}$

\section{Understanding barriers to accessing healthcare}

Homelessness is multifactorial, with domestic violence, unstable employment, mental health factors and housing affordability being some of the key drivers, ${ }^{4}$ but one factor that seems to be common among people experiencing homelessness is disengagement from social supports and services, including health services. ${ }^{5,6}$ During chance encounters and ensuing routine conversations with many people experiencing homelessness, it became evident that, in terms of healthcare, the needs of people who are homeless are complex. Traditional healthcare delivery models are proving inadequate in addressing them. Reasons that people who are homeless reported for not accessing healthcare include the dread of the doctor's waiting room because of discrimination by staff and other patients visiting the practice $;^{7}$ perception of a power differential with doctors; ${ }^{8}$ lack of transportation, identity proof and Medicare card; ${ }^{9}$ and poverty. ${ }^{10}$ As a result of these barriers, medical care is usually sought only in advanced stages when treatment becomes more expensive and morbidity becomes high. ${ }^{11}$

\section{The solution}

The solution lies in taking healthcare to people who are homeless. The Freo Street Doctor does this using a mobile general practice in a van across locations 
in Fremantle, Cockburn and Melvile. ${ }^{12}$ Others like Living Room ${ }^{13}$ in Melbourne and Homeless Healthcare ${ }^{8}$ in Perth have established medical services in community drop-in centres. In Adelaide, most drop-in centres have nurses and first aid staff on duty, but not doctors. Many doctors in Adelaide provide services to people who are homeless, and the nursing staff at the drop-in centres routinely refer to them. However, to be seen by the doctors, the patients have to visit the practice, and the numerous barriers mentioned earlier prevent this visit.

Access Clinic was established by a group of Flinders University College of Medicine and Public Health students to address the gap in the healthcare needs of people who are homeless in Adelaide. The clinic was based on the model of University of California San Diego Student-Run Free Clinic Project in San Diego, USA. ${ }^{14}$

\section{Flinders Student-Run Free Clinic Project - Access Clinic} After obtaining a 'no objection' to the project from the medical school, a free health clinic was set up at the Vinnies Men's Crisis Centre, a crisis accommodation, meals and support centre for men who are homeless in Adelaide. The clinic ran for four hours every Saturday and Sunday and was staffed by medical students and supervised by doctors. No prior appointments were necessary to access the clinic. Students triaged and created paper records for each patient. These were kept confidentially.

Each consultation was carried out by one preclinical year student and one clinical year student. After taking a detailed history and doing a physical exam, the students presented the case to the supervising doctor. The doctor confirmed the diagnosis and prepared management plan after taking the patient's goals and circumstances into consideration. The students then explained the diagnosis and the management plan to the patient.

Studies have shown that the act of signing a contract increases conformity to the contract. ${ }^{15}$ Therefore, to encourage the patients to take ownership of their own health, the management plan was established to be a contract between the patient, the students and the doctor. Whether this actually increased the rates of compliance to therapy was not investigated. A copy of the plan was kept in the patient's records.

Blood pressure measurements were routinely performed, and dietary and other lifestyle advice was always given, keeping the practicalities of the patients in mind. Wound care, mental health first aid and referrals to specialists, allied health services and legal services were the other activities of the clinic.

\section{Facilitating links to mainstream general practice services}

At first contact with the clinic, we found that a majority of our patients did not have a regular general practitioner (GP). At each new consultation, preventive health activities such as the absolute cardiovascular disease risk assessment, the Australian type 2 diabetes risk assessment and depression screening using PHQ-9 were undertaken. This was done with the dual aims of having a springboard for discussions about healthy lifestyles, substance abuse and smoking, and to encourage making contact with a mainstream GP. Patients found to be at high risk were educated about the condition and the need to see a mainstream GP to maintain continuity of care for chronic disease management.

Transportation and escort were arranged by the students for the first visit to the GP. Most patients who visited a mainstream GP stopped or reduced their frequency of use of Access Clinic and reported making follow-up appointments with the GPs. In this way, Access Clinic acted as a bridge between existing health services and the people experiencing homelessness accessing services at the crisis centre.

\section{Reflections}

Student-run clinics not only address a community health need, they also address the need for student placements. Apart from providing medical services to the patients, the student volunteers also acquired valuable practical experience in established, managing and the day-to-day running of a medical clinic, and gained knowledge of the various regulatory requirements to which a general practice in Australia must adhere. The service was well used, with each session attended by 12 patients on average, with a mix of both new and repeat patients. The service was marketed to the target clientele by word of mouth.

The main problems encountered were medication-seeking behaviours of some patients, and ensuring continuity of care. The former was addressed by not prescribing any medications with addictive potential as a matter of policy. The latter could not be addressed because of scheduling issues with students and doctors. Patients not filling prescriptions because of limited finances was another problem identified. It was partially addressed by dispensing a limited formulary of donated medications. The students endeavoured to partner with pharmacies to fill prescriptions under their corporate social responsibility schemes, but this did not fully materialise.

The project won the Flinders University Health and Human Rights Group's Health Equity Action Together (HEAT) grants consecutively in 2015 and 2016, and operated in 2016 and 2017. It had to close in 2018 as a result of attracting a far greater number of patients than there were resources to care for, and difficulties in finding doctors to supervise the clinic. Student-run clinics are well established in North America and are sustainable because of their affiliation with a medical school. The doctors supervising the clinics are usually salaried or formally appointed volunteer staff of the medical schools. ${ }^{13}$ This enables greater risk mitigation and availability of resources. Elective term placement at these clinics is possible. ${ }^{13}$

Conversely, Access Clinic was completely a student initiative, with no affiliation to Flinders University College of Medicine and Public Health. There was an opportunity to receive additional funding, and students at the clinic were approached by other drop-in centres to establish secondary sites for Access Clinic, but without affiliation to the school, it 
was difficult to find clinical supervisors. Hence, the clinic proved unsustainable. If student-run clinics are to be successful in Australia in the future, similar to their North American counterparts, they will need to be affiliated with a medical school. In addition, it should be possible for students to do an elective placement with them, thus enabling sustainability and aiding evaluation.

\section{Author}

Laalithya Konduru BTech, MS, medical student, Flinders University College of Medicine and Public Health, SA. laalithya@gmail.com

Funding: The clinic was funded by the Flinders University Health and Human Rights Group (HHRG) Health Equity Action Together (HEAT) grants 2015 and 2016. HHRG played no role in the preparation of this manuscript.

Competing interests: None.

Provenance and peer review: Not commissioned, externally peer reviewed.

\section{Acknowledgements}

I would like to thank Flinders University Health and Human Rights Group for believing in the project and conferring the Health Equity Action Together (HEAT) grant twice consecutively and making Access Clinic possible. I would like to express my sincerest thanks to Tony Roach, Manager at Vinnies Men's Crisis Centre, for his support of the clinic. I would also like to express my gratitude to the students, staff and the doctors who gave their valuable time to the clinic, and the patients who used the clinic and contributed to the students' learning.

\section{References}

1. UN General Assembly. Universal Declaration of Human Rights, 217 (III) A: United Nations. Paris: 1948. Available at www.un.org/en/universaldeclaration-human-rights/index.html [Accessed 2 September 2019].

2. Homelessness Australia. Homelessness statistics. NSW: Homelessness Australia, 2019. Available at www.homelessnessaustralia.org. au/about/homelessness-statistics [Accessed 2 September 2019].

3. Carlisle P. Preventative health care submission to joint select committee parliament of Tasmania: Submission on behalf of Bethlehem House Inc. Hobart: Bethlehem House Inc, 2013.

4. Pawson H, Parsell C, Saunders P, Hill T, Liu E. Australian homelessness monitor 2018. Collingwood, Vic: Launch Housing, 2018.

5. Muñoz M, Vázquez C, Bermejo M, Vázquez JJ. Stressful life events among homeless people: Quantity, types, timing, and perceived causality. J Community Psychol 1999;27(1):73-87. doi: 10.1002/(SICI)15206629(199901)27:1<73::AID-JCOP5>3.0.CO;2-\%23

6. Moore G, Gerdtz M, Manias E. Homelessness, health status and emergency department use: An integrated review of the literature. Australas Emerg Nurs J 2007;10(4):178-85. doi: 10.1016/j. aenj.2007.07.003.

7. Strange $C$, Fisher $C$, Arnold-Reed D, Brett $T$, Ping-Delfos WCS. A general practice street health service: Patient and allied service provider perspectives. Aust J Gen Pract 2018;47(1-2):44-48

8. Davies A, Wood LJ. Homeless health care: Meeting the challenges of providing primary care. Med J Aust 2018;209(50):230-34. doi: 10.5694/ mja17.01264.

9. Australian Human Rights Commission. Homelessness is a human rights issue. Sydney, NSW: Australian Human Rights Commission, 2008. Available at www.humanrights.gov.au/ our-work/rights-and-freedoms/publications/ homelessness-human-rights-issue\#8 [Accessed 2 September 2019].
10. Wise C, Phillips K. Hearing the silent voices: Narratives of health care and homelessness. Issues Ment Health Nurs 2013;34(5):359-67. doi: 10.3109/01612840.2012.757402.

11. Baggett TP, O'Connell JJ, Singer DE, Rigotti NA. The unmet health care needs of homeless adults: A national study. Am J Public Health 2010;100(7):1326-33. doi: 10.2105/ AJPH.2009.180109.

12. Black Swan Health. Freo Street Doctor. Osborne Park, WA: Black Swan Health, 2017. Available at www.blackswanhealth.com.au/services/primaryhealth-services/freo-street-doctor/ [Accessed 2 September 2019].

13. Youth Projects. The Living Room. Glenroy, Vic: Youth Projects, 2017. Available at https:// youthprojects.org.au/programs/living-room [Accessed 2 September 2019].

14. Beck E. The UCSD Student-Run Free Clinic Project: Transdisciplinary Health Professional Education. J Health Care Poor Underserved 2005;16(2):207-19. doi: 10.1353/hpu.2005.0026.

15. Kettle K, Häubl G. The Signature Effect: Signing influences consumption-related behavior by priming self-identity. J Consum Res 2011;38(3):474-89. doi: 10.1086/659753. 